\title{
Overexpression of members of the microRNA-183 family is a risk factor for lung cancer: A case control study
}

\author{
Wangyu Zhu ${ }^{2 \dagger}$, XiaoGuang $\mathrm{Liu}^{2 \dagger}{ }^{+}$, JianYing He${ }^{2}$, DongDong Chen ${ }^{2}$, YanYan Hunag ${ }^{2}$ and Yong Kui Zhang ${ }^{*}$
}

\begin{abstract}
Background: Lung cancer is the leading cause of cancer-related deaths worldwide. Early detection is considered critical for lung cancer treatment. MicroRNAs (miRNAs) have shown promise as diagnostic and prognostic indicators. This study was to identify specific miRNAs with diagnostic and prognostic value for patients with lung cancer, and to explore the correlation between expression profiles of miRNAs and patient survival.

Methods: Gene expression of members of the miR-183 family (miR-96, miR-182, and miR-183) were examined in 70 paired samples from lung cancer patients (primary cancer and non-cancerous tissues and sera), as well as 44 serum samples from normal volunteers and lung cancer cell lines by quantitative real-time reverse transcription polymerase chain reaction (RT-qPCR). The correlation between the expression of miRNAs in tissues, sera, and patient overall survival were also examined by log-rank and Cox regression analysis.
\end{abstract}

Results: Expression levels of members of the miR-183 family in lung cancer tumor and sera were higher than that of their normal counterparts. The miR-96 expression in tumors was positively associated with its expression in sera. Log-rank and Cox regression analyses demonstrated that high expression of tumor and serum miRNAs of the miR183 family were associated with overall poor survival in patients with lung cancer.

Conclusions: Our results suggest that the expressions of miR-96, miR-182, and miR-183 in tumor and sera may be considered potential novel biomarkers for the diagnosis and prognosis of lung cancer.

Keywords: miRNA, diagnosis, prognosis, sera, RT-quantitative PCR, human lung cancer

\section{Background}

Lung cancer is the leading cause of cancer-related deaths worldwide [1], and the current pathologic staging is inadequate to predict outcome for patient treatment. The development of molecular target therapy has improved the management of patients with lung cancer who are at high risk of relapse following surgery. One of the most promising classes of molecular markers in tumor prognosis is the small noncoding RNAs, or microRNAs (miRNAs) [2-4]. MiRNAs, acting as oncogenes or tumor suppressors, have been shown to regulate the expression of hundreds of targeted genes at the

\footnotetext{
* Correspondence: zyk801801@126.com

+ Contributed equally

'Department of Cardio-Thoracic Surgery, Zhoushan Hospital of Zhejiang

Province, Zhoushan, Zhejiang, 316004, 316004, China Full list of author information is available at the end of the article
}

posttranscriptional level and are implicated in the pathogenesis and therefore prognosis of human cancers [5-9]. For non-small cell lung cancer (NSCLC) in particular, previous reports have indicated that miRNA expression patterns could be potential biomarkers used for diagnosis, prognosis, and personalized therapy [4,8-11]. In addition, some studies found that human serum or plasma contained large numbers of stable miRNAs and that the expression profiles of some specific circulating miRNAs could be useful in the diagnosis and prognosis of cancer [12-14].

In our study, we performed a miRNA expression array by quantitative real-time reverse transcription polymerase chain reaction (RT-qPCR) and identified the expression of members of the miR-183 family (miR-96, miR182 , and miR-183) when comparing primary NSCLC tumor with adjacent normal lung tissues. The miR-183
C Biomed Central 
family is located on human chromosome 7 and members of this family have been identified as potential oncogenes in several tumor types, including medulloblastomas [15], breast cancer [16], prostate cancer [17], hepatocellular tumors [18], and colon cancer [19,20], as well as lung cancer $[21,22]$. However, the role that these miRNAs play in the diagnosis and prognosis of lung cancer patients remains unknown.

We compared the expression levels of the miR-183 family in lung cancer cell lines with normal lung cells, and in primary tumor tissues and sera from NSCLC patients with normal volunteers. Our results indicate for the first time that members of the miR-183 family expressed in tumors and sera may be potential biomarkers in the diagnosis and prognosis of human lung cancer.

\section{Methods}

Sample population

NSCLC and matched adjacent noncancerous tissues were collected from patients undergoing lung resection surgery from January 2008 to May 2008 at Zhoushan Hospital, Zhejiang Province, China. The details of patients were shown in Table 1. Eligible samples were obtained from primary lung cancer that had not received any preoperative radiotherapy or chemotherapy, and in which there was no co-existing disease. Moreover, we excluded tissue blocks of mixed histology, or specimens with insufficient tumor material. The subtypes included 36 squamous-cell carcinoma and 34 adenocarcinoma. All human materials were obtained with patients' informed consent and the Ethical Review Committee of Zhoushan Municipal Government of China approved this study.

Upon removal, the surgical specimens were immediately transported to the clinical pathology laboratory, where each sample was placed in a cryovial and flashfrozen in liquid nitrogen within 30 minutes and then stored at $-80^{\circ} \mathrm{C}$ until analyzed. Sera from all NSCLC patients and healthy volunteers were also collected. There was no significant difference in gender or age between NSCLC patients and healthy volunteers. All cases were reviewed by two pathologists and diagnoses were confirmed according to the criteria recently established by the National Comprehensive Cancer Network (NCCN).

\section{Cell lines and cell culture conditions}

The following cell lines were cultured individually in RPMI-1640 medium (Gibco): A549, H1299, and SPC-A1 human lung adenocarcinoma; 95C and 95D human giant-cell lung carcinoma; NCI-H466 human small cell lung carcinoma; NCI-H460 human large-cell lung carcinoma; and human bronchial epithelia. In addition, SK-
Table 1 Clinico-pathological Characteristics of 70 Patients with NSCLC

\begin{tabular}{|c|c|}
\hline Characteristics & $\mathrm{n}$ \\
\hline \multicolumn{2}{|l|}{ Mean age } \\
\hline$<60$ & 34 \\
\hline$\geq 60$ & 36 \\
\hline \multicolumn{2}{|l|}{ Sex } \\
\hline Male & 56 \\
\hline Female & 14 \\
\hline \multicolumn{2}{|l|}{ Smoking } \\
\hline Nonsmokers & 24 \\
\hline Current smokers & 46 \\
\hline \multicolumn{2}{|l|}{ Tumor size } \\
\hline $0-3 \mathrm{~cm}$ & 18 \\
\hline$>3 \mathrm{~cm}$ & 52 \\
\hline \multicolumn{2}{|c|}{ Histological classification } \\
\hline Adenocarcinoma & 34 \\
\hline SCC & 36 \\
\hline \multicolumn{2}{|c|}{ Invasion to lung membrane } \\
\hline Yes & 17 \\
\hline No & 53 \\
\hline \multicolumn{2}{|l|}{ differentiation } \\
\hline Mod-well & 46 \\
\hline Poor & 24 \\
\hline \multicolumn{2}{|l|}{ Lymph node } \\
\hline Negative & 38 \\
\hline Positive & 32 \\
\hline \multicolumn{2}{|l|}{ Stage classification } \\
\hline Stagel & 36 \\
\hline Stagell,III and IV & 34 \\
\hline
\end{tabular}

MES1 human squamous-cell lung carcinoma cells were cultured in Dulbecco's modified Eagle's medium (DMEM; Gibco). Both media were supplemented with $10 \%$ fetal bovine serum (Gibco), $2 \mathrm{mM}$ L-glutamine, 100 $\mathrm{IU} / \mathrm{mL}$ penicillin, and $100 \mathrm{mg} / \mathrm{mL}$ streptomycin. Cells were incubated in $5 \% \mathrm{CO}_{2}$ at $37^{\circ} \mathrm{C}$.

\section{RNA isolation}

Total RNA isolated from 6 NSCLC and 6 matched adjacent noncancerous tissues by the Trizol (Invitrogen) method were prepared for miRNA microarray according to the manufacturer's instructions. miRNA isolated from cells, tissues, and sera were obtained using the miRNA Isolation Kit and mirVana PARIS Kit (Applied Biosystems, Foster City, CA, USA), according to the manufacturer's protocol. The specific sources of miRNAs were: $10^{6}$ to $10^{7}$ cells (described above), $100 \mathrm{mg}$ of tissue from each of 70 NSCLC patients and matched adjacent noncancerous tissues, and circulating miRNAs from $600 \mu \mathrm{L}$ of serum from each of 70 NSCLC patients and 44 normal volunteers. The RNA concentration was measured by a NanoDrop ND-1000 spectrophotometer (nm 
readings: A260/280 > 2.0, A260/230 > 1.8; NanoDrop Technologies).

\section{MicroRNA microarray and data analysis}

Three to five micrograms of total RNA were labeled by ligating the fluorescent RNA-linker 5'-cytidine bisphosphate-cyanine 3 ( $\mathrm{pCp}-\mathrm{Cy} 3$ ) to the 3 ' end of miRNAs. Slides were then incubated with the labeled RNA and washed. Five hundred and nine miRNAs passed the initial screening criteria of the normalized median fluorescence signal. The images were analyzed using SpotReader software (Niles Scientific, Portola Valley, CA). The significance of differences in expression levels was assessed by a two-sided paired $t$-test within the significance analysis of microarrays (SAM). $P<0.05$ indicated a significant difference.

\section{RT-qPCR of miRNA derived from lung cancer cell lines and lung primary tissues}

The amounts of the miRNAs in lung tumors, analyzed by microarray, were quantified by RT-qPCR using TaqMan MicroRNA Assay Kits (Applied Biosystems, USA). Briefly, the reverse transcription (RT) reaction was carried out with a TaqMan MicroRNA Reverse Transcription Kit (Applied Biosystems) according to the instruction of the protocol. One to ten nanograms of total RNA per $15 \mu \mathrm{L}$ RT reaction were processed at $16^{\circ}$ $\mathrm{C}$ for $30 \mathrm{~min}, 42^{\circ} \mathrm{C}$ for $30 \mathrm{~min}$, and $85^{\circ} \mathrm{C}$ for $5 \mathrm{~min}$. Following the RT, quantitative real-time PCR was performed in an ABI 7500 Real-Time PCR system (Applied Biosystems) at $95^{\circ} \mathrm{C}$ for $10 \mathrm{~min}$, followed by 40 cycles of $95^{\circ} \mathrm{C}$ for $15 \mathrm{~s}$ and $60^{\circ} \mathrm{C}$ for one minute.

The cycle threshold $(\mathrm{Ct})$ values were calculated with SDS 2.0.1 software (Applied Biosystems). The average expression levels of miRNAs in tissues and sera were normalized with U6 small nuclear RNA (snRNA) and U48 snRNA using the $2^{-\Delta \Delta \mathrm{Ct}}$ method [23]. The mean $\mathrm{Ct}$ value in three candidate miRNAs was calculated, excluding outliers (i.e., replicates with a $\mathrm{Ct}$ differing by $>$ one cycle from the median). If $\mathrm{Ct}_{\mathrm{U} 6}$, ave and $\mathrm{Ct}_{\mathrm{U} 48 \text {, ave }}$ were not within 20 and 32 cycles, the assay was repeated. Samples with low U6 or U48 snRNA levels were not included in this study.

\section{Statistical analyses}

The statistical analyses were performed with Graphpad Prism 5.0 statistical software. The data were examined according to the degree of homogeneity. The paired $t$ test, unpaired $t$-test, or Mann-Whitney $U$-test was used to analyze the correlation between the miRNA expression levels and clinical-pathological features of the patients. The paired sample $t$-test was used to compare the differences in miRNA expression between lung tissues and sera. All data were expressed as the mean \pm standard error of the mean (SEM). Binary logistic regression was used to assess associations between the miR-183 family and the clinical-pathological features of the patients. Survival analysis was performed with the Kaplan-Meier method, and the log-rank test was used to compare survival times between groups and was adjusted according to age and tumor stages. The Cox hazard regression model was used to analyze the miRNAs as risk factors for lung cancer. A probability $(P)$ value $<0.05$ was considered statistically significant.

\section{Results}

\section{Expression of the miR-183 family of miRNAs in lung} tissues, sera, and cell lines

MicroRNA arrays were performed from 6 lung cancer and 6 matched adjacent normal lung tissues that contained 723 human miRNA probes (from version 10.0 of miRBase sequence database, http://www.mirbase.org/). A total of 94 miRNAs were differentially expressed between lung carcinoma and the normal counterpart. Among those, we selected for further study 3 cluster miRNAs, namely miR-96, miR-182, and miR-183, based on the magnitude of fold changes (10.77-, 10.75-, and 6.62 -fold, respectively) and probability values $(P=$ $0.00127,0.00209$ and 0.00190$)$, as shown in our previous study [24].

We validated the three miRNAs in 70 pairs of lung carcinoma and the corresponding noncancerous lung tissues by RT-qPCR. We showed that, compared with the adjacent normal lung tissues, the levels of the mature forms of miR-96, miR-182, and miR-183 were significantly increased in lung cancer tissues $(P<0.0001$ for each; Figure 1A). The highly expressed (> 2-fold changes) miR-96, miR-182 and miR-183 were observed in $42(60.0 \%), 54(77.1 \%)$ and $48(68.6 \%)$ of the 70 samples, respectively.

Compared to the sera of normal volunteers, the expression levels of miR-96, miR-182, and miR-183 in the sera of NSCLC patients were significantly higher in 62 (88.6\%), $38(54.3 \%)$, and $32(45.7 \%)$ of the 70 samples $(P<0.0001,=0.0130$, and $=0.0086$, respectively; Figure 1B). A correlation was also found between the serum and tumor levels of miR-96 (Pearson $r=0.419, P=$ 0.0003 ), but not for miR-182 (Pearson $r=0.0464, P=$ 0.703 ) or miR-183 (Pearson $r=0.118, P=0.332$ ). This suggested that serum levels of miR-96, but not miR-182 and miR-183, might correspond to the levels of tumor miR-96 (Figure 2)

Finally, we tested levels of miRNAs in different types of lung cancer vs. normal cell lines. The results from RT-qPCR were expressed as fold changes in each miRNA in lung cancer cells relative to normal cells. As shown in Figure 3, the expression levels of miR-96 were higher in 8 lung cancer cell lines. High levels of miR- 


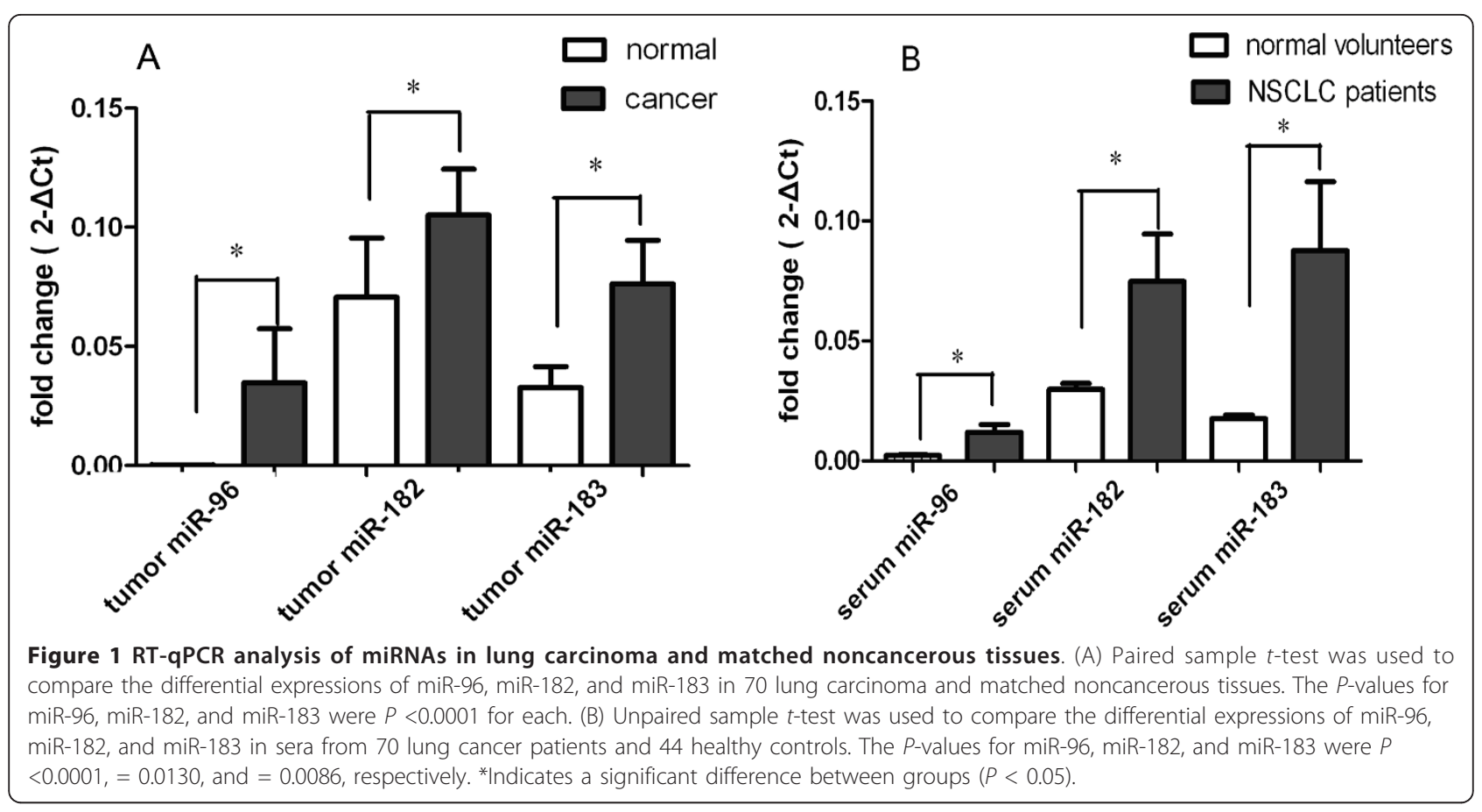

182 were found in H466 and A549 cells, and high levels of miR-183 in H466 and SK-MES1. The highest expression levels for the three miRNAs were found in NCIH466 cells. In addition, the expression levels of all three were higher in A549 and 95D cells than in H1299 and 95C cells.

Correlation between miR-183 family and clinicalpathological features of NSCLC

We also analyzed with the Mann-Whitney $U$-test the correlation between miRNAs and clinical-pathological features of NSCLC (including age, gender, smoking history, histological classification, lymph node metastasis, differentiation, and clinical-pathological stage) to understand better the potential role of these miRNAs in NSCLC development and progression. Our results showed that overexpression of miR-183 in tumors was strongly associated with lymph node metastasis, invasion of the lung membrane, and advanced clinical stage of NSCLC $(P=0.0086,0.0222$ and 0.0478 , respectively). Overexpression of miR-182 in tumors was positively related to invasion of the lung membrane and tumor size $>3 \mathrm{~cm}(P=0.0140$ and 0.0464 , respectively). In sera, miR-182 overexpression was also positively related to invasion of the lung membrane and tumor size $>3 \mathrm{~cm}(\mathrm{P}$ $=0.0222$ and 0.0351 , respectively). Compared to lung adenocarcinoma, higher expression of miR-96, miR-182, and miR-183 in tumors, and miR-96 in sera, were found in squamous cell lung carcinoma $(P=0.0216,0.0190$, 0.0042, and 0.0310, respectively; Figure 4).

We also analyzed the association between levels of the miR-183 family and clinical-pathological features with a
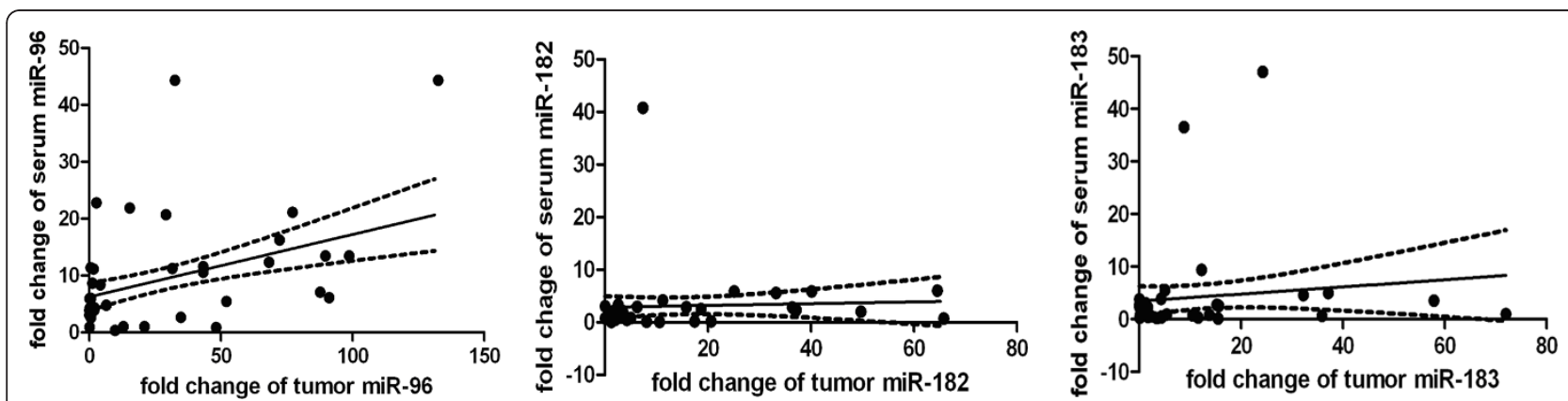

Figure 2 Correlation between the expressions of miR-96, miR-182, and miR-183 in tissues vs. sera from lung cancer patients. Pearson's correlation between the expression of miR-96, miR-182, and miR-183 in NSCLC tissues and sera are shown. The correlation rate of miR-96 was $0.419, P=0.0003 ;$ miR-182 was $0.0464, P=0.703$; and miR-183 was $0.118, P=0.332$. 


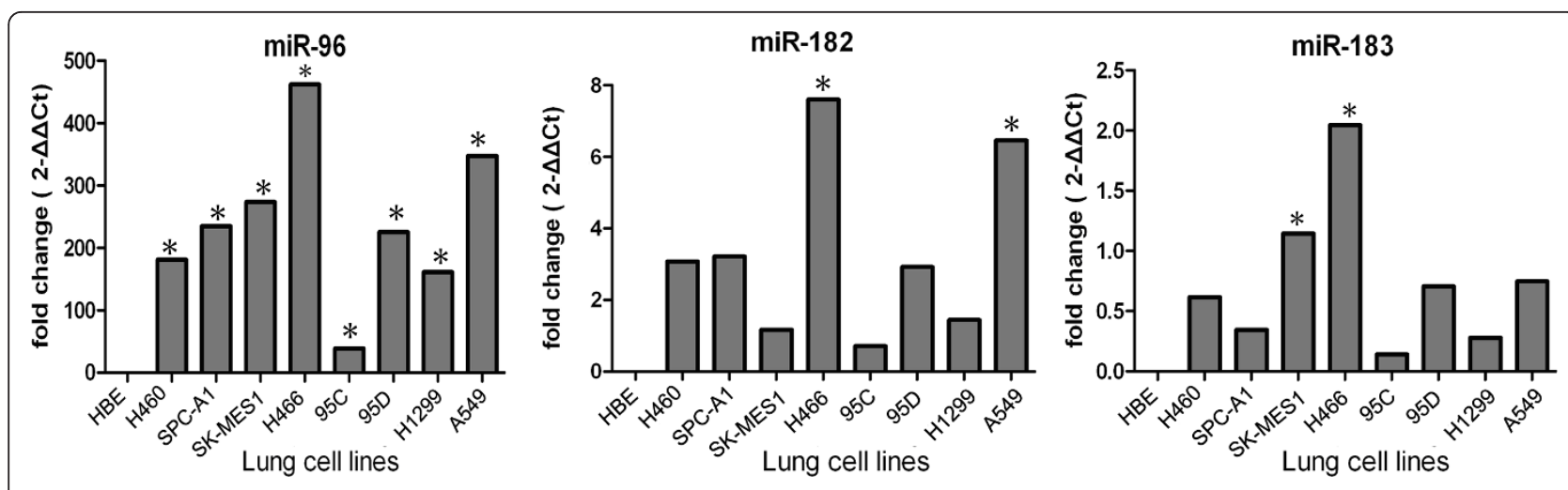

Figure 3 RT-qPCR analysis of lung cancer cell lines. Total RNA was isolated from several different lung cancer cells lines by the Trizol method (Invitrogen) according to the manufacturer's instructions, and qRT-PCR was performed using TaqMan MicroRNA Assay Kits (Applied Biosystems). The average expression levels of miR-96, miR-182, and miR-183 in tissues and sera were normalized using the $2^{-}{ }^{\Delta \mathrm{C} t}$ method relative to the average of U6 snRNA and U48 snRNA. The average Ct value of triplicates in three candidate miRNAs was calculated. *Indicates a significant difference compared to HBE cells $(P<0.05)$.

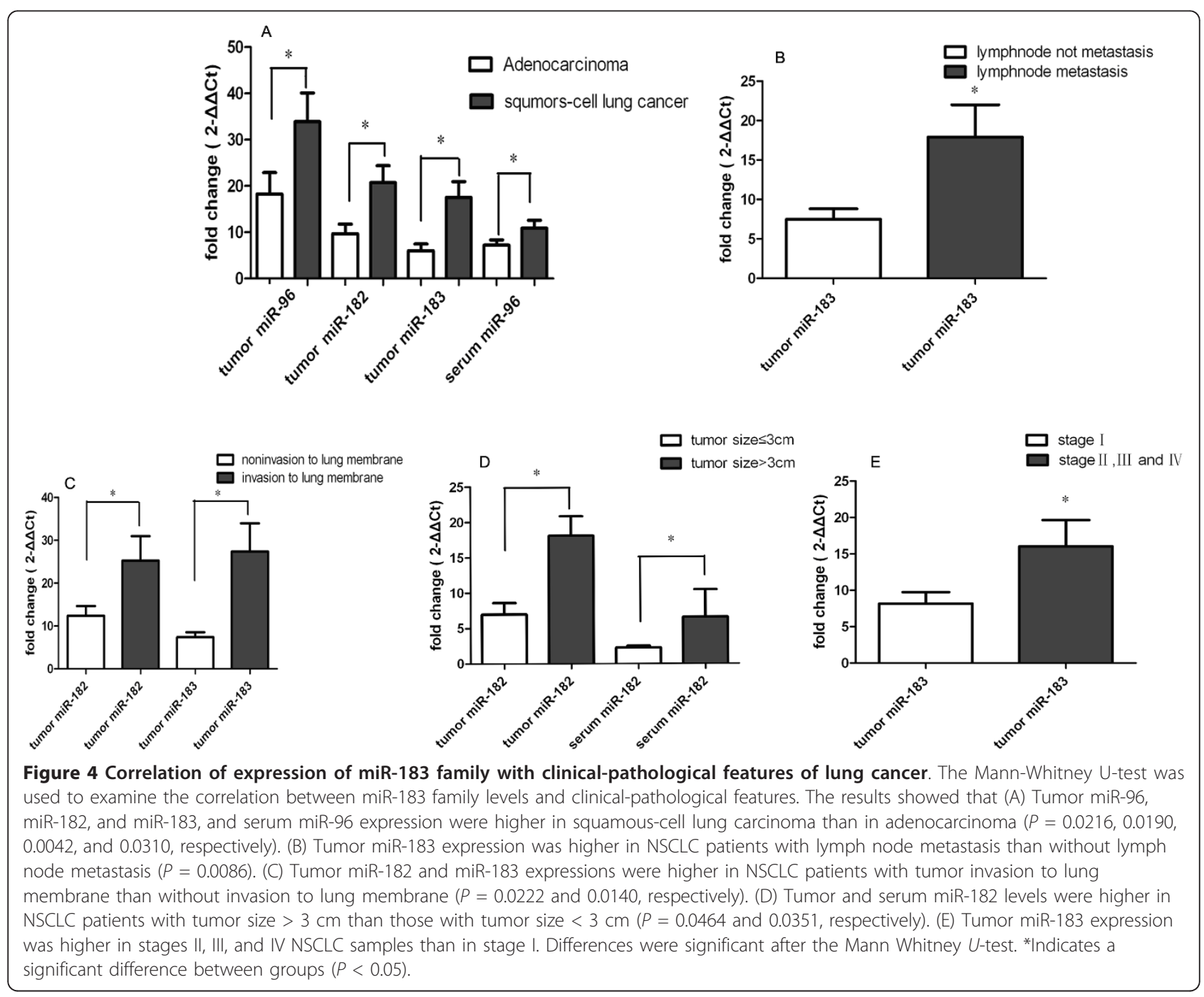


binary logistic regression model. Results showed that patients over 60 years old, or with squamous-cell lung carcinoma, had higher levels of tumor miR-96. Patients with squamous-cell lung carcinoma or tumor invasive to lung membrane had higher levels of tumor miR-183. Patients with poor differentiation had higher levels of miR-96, miR-182 and miR-183 in sera (Table 2).

\section{Correlation between expression of miRNAs of the miR- 183 family and overall survival of NSCLC patients}

Next, we investigated whether the expressions of miR96, miR-182, and miR-183 were correlated with overall survival of NSCLC patients. Specifically, we used the Kaplan-Meier method, log-rank test and univariate Cox hazard regression model to analyze the correlation between overall survival of NSCLC patients and the expressions of miR-96, miR-182, and miR-183 in tumors (medians of $2^{-\Delta \Delta \mathrm{Ct}}$ values: $6.45,6.25$, and 4.44 , respectively) and in sera (medians 5.98, 2.08, and 1.84). The results showed that high expressions of miR-96, miR182 and miR-183 in tumors and sera were independently correlated with shorter overall survival of NSCLC patients (log-rank test: $P=0.0039,0.0027,0.0053$, respectively in tumors, and $P=0.0017,0.0025$, and 0.0046 in sera; Figure 5).

We also examined if the expressions of miR-96, miR182, and miR-183 in tumors and sera were correlated with clinical-pathological features of the patients, with hazard ratios (adjusted for sex, age and tumor stage) of $9.637,7.163,8.616, P=0.005,0.010$, and 0.005 respectively in tumors and with hazard ratios (adjusted for sex, age and tumor stage) of 5.512, 5.327, 5.972 yielded $P=$ $0.027,0.030$, and 0.022 respectively (Table 3 ) in sera. This result suggested that miR-96, miR-182 and miR-
183 in tumor and sera independently contributed to the overall survival of lung cancer patients

\section{Discussion}

Lung carcinoma is one of the most common malignancies in the world, and is the leading cause of cancer death in men and women in the United States with a dismal five-year survival rate $(<15 \%)$ [1]. Although recent advances have been made in improving diagnosis and treatment strategies, the prognosis of lung cancer patients remains unchanged and early detection is critical in improving survival duration. Studies have shown that miRNAs play an important role in tumorigenesis and they have been considered potential biomarkers for early diagnosis and prognosis in a wide variety of human cancers $[6,14,25,26]$. More importantly, circulating miRNAs might act as noninvasive blood-based biomarkers for cancer diagnosis $[14,27]$. One recent report demonstrated that miRNAs in tissues and plasma could have a critical role as molecular predictors of lung cancer development and management outcome [28].

The upregulation of members of the miR-183 family (miR-96, miR-182, miR-183) has been reported in several types of cancers [15-20]. Consistent with our results, members of the miR-183 family were elevated in lung cancer, revealed by novel rank-based statistical methods using microarrays $[21,22,29]$. miR-96, a known onco-miRNA, targets the tumor suppressor gene forkhead box O3 (FOXO3; a transcription factor that plays important roles in tumorigenesis) by binding to the 3UTR of FOXO3 mRNA and thereby mediating protection against apoptosis and promoting cell survival $[16,30]$. Studies have also reported that miR-27a, miR96 , miR-182, and miR-183 coordinately regulated the

Table 2 Binary logistic regression analysis for an association between the expression levels of the miR-183 family and clinical-pathological features of patients

\begin{tabular}{|c|c|c|c|}
\hline & subset & $\begin{array}{l}\text { Exp (B) } \\
\text { (95\% confidence interval) }\end{array}$ & $P$-value \\
\hline Tumor miR-96 & High, $>6.45 /$ low, $<6.45$ & & \\
\hline Age & $<60 / \geq 60$ & $2.857(1.080-7.559)$ & $0.034^{*}$ \\
\hline Histological classification & adenocarcinoma/SCC & $3.667(1.366-9.842)$ & $0.010^{*}$ \\
\hline Tumor miR-183 & High, $>4.44 /$ low, $<4.44$ & & \\
\hline Histological classification & adenocarcinoma/SCC & $3.667(1.366-9.842)$ & $0.010^{*}$ \\
\hline Invasion to lung membrane & Negative/positive & $3.750(1.072-13.121)$ & $0.039 *$ \\
\hline Serum miR-96 & High, $>5.98 /$ low,$<5.98$ & & \\
\hline Differentiation & poor/Mod-well & $0.321(0.114-0.905)$ & $0.032^{*}$ \\
\hline Serum miR-182 & High, $>2.08 /$ low, $<2.08$ & & \\
\hline Differentiation & poor/Mod-well & $0.178(0.059-0.537)$ & $0.002^{*}$ \\
\hline Serum miR-183 & High, $>1.84 /$ low,$<1.84$ & & \\
\hline Differentiation & poor/Mod-well & $0.321(0.114-0.905)$ & $0.032^{*}$ \\
\hline
\end{tabular}

Binary logistic regression analysis. *Indicates a significant difference $(P<0.05)$. 


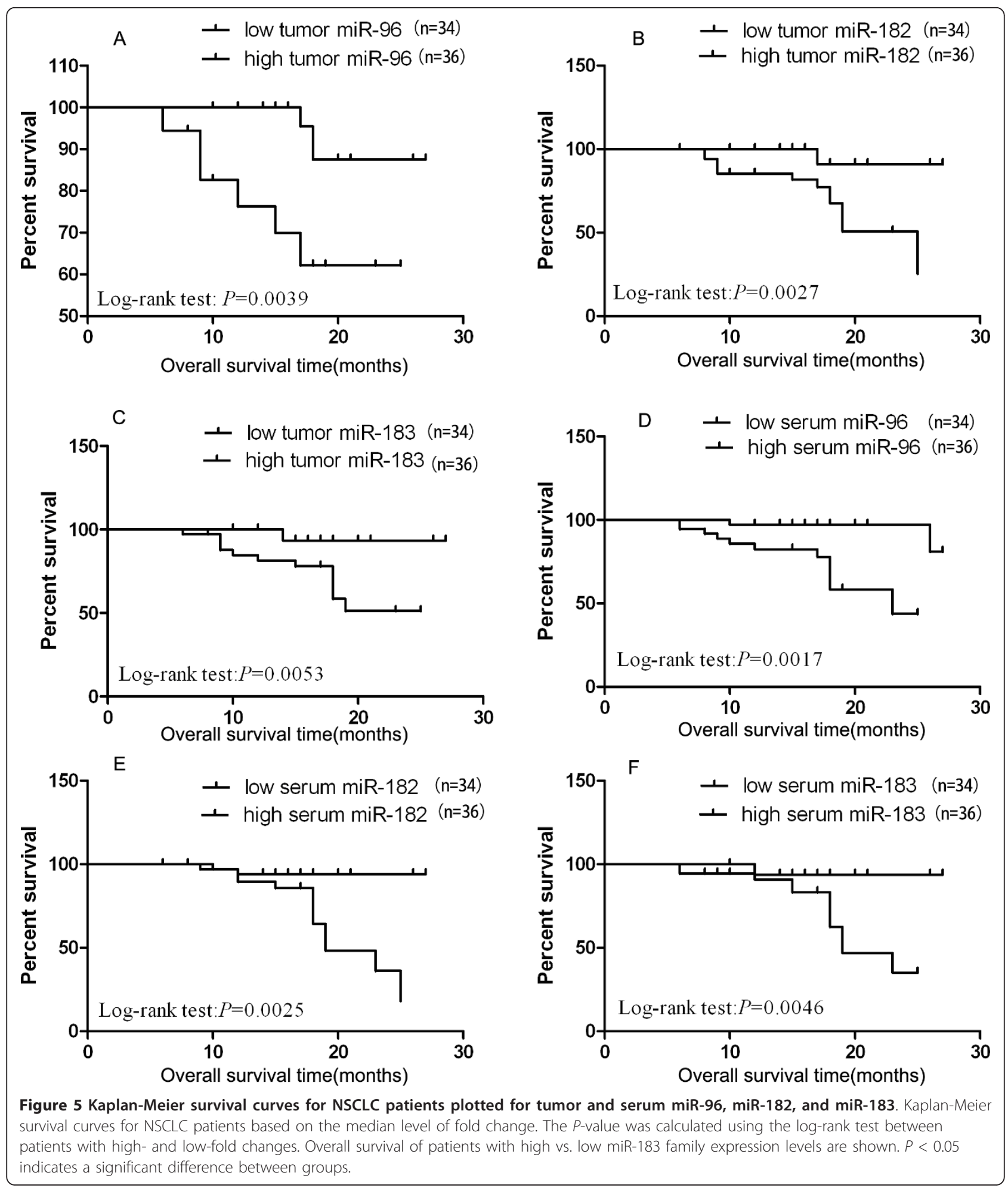

expression of forkhead box O1 (FOXO1) by directly targeting the mRNA FOXO1 3'-UTR [31,32]. In addition, miR-183 functioned as an onco-miRNA, shown to target the tumor suppressor transcription factor early growth response 1 (EGR1), and phosphatase and tensin homo$\log (P T E N)$ to promote tumor cell migration [19].

Consistent with other reports $[6,19,32]$, we showed that compared to adjacent non-cancerous lung tissues 
Table 3 Univariate Cox hazard regression analysis for prognostic factors

\begin{tabular}{|c|c|c|c|}
\hline & subset & $\begin{array}{l}\text { Adjusted Hazard ratio } \\
\text { (95\% confidence interval) }\end{array}$ & $P$-value \\
\hline Gender & male/female & $0.031(0.000-5.569)$ & 0.190 \\
\hline Age & $<60 / \geq 60$ & $1.630(0.564-4.716)$ & 0.367 \\
\hline Smoking & nonsmoker/current smoker & $1.388(0.306-6.297)$ & 0.671 \\
\hline Tumor size & $0-3 \mathrm{~cm} />3 \mathrm{~cm}$ & $0.766(0.239-2.455)$ & 0.654 \\
\hline Histological classification & adenocarcinoma/sCC & $2.739(0.781-9.604)$ & 0.115 \\
\hline Invasion to lung membrane & Negative/positive & $1.000(0.221-4.534)$ & 1.000 \\
\hline Differentiation & Mod-well/poor & $0.757(0.182-3.141)$ & 0.701 \\
\hline Lymph node & Negative/positive & $1.279(0.425-3.850)$ & 0.661 \\
\hline Stage classification & stage I/stage II, III, IV & $1.001(0.334-2.996)$ & 0.999 \\
\hline Tumor miR-96 & High, $>6.45 /$ low, $<6.45$ & $9.637(1.963-47.315)$ & $0.005 *$ \\
\hline Tumor miR-182 & High, $>6.25 /$ low, $<6.25$ & $7.163(1.597-32.138)$ & $0.010 *$ \\
\hline Tumor miR-183 & High, $>4.44 /$ low,$<4.44$ & $8.616(1.918-38.705)$ & $0.005^{*}$ \\
\hline Serum miR-96 & High, $>5.98 /$ low,$<5.98$ & $5.512(1.219-24.915)$ & $0.027 *$ \\
\hline Serum miR-182 & High, $>2.08 /$ low,$<2.08$ & $5.327(1.181-24.030)$ & $0.030 *$ \\
\hline Serum miR-183 & High, $>1.84 /$ low,$<1.84$ & $5.972(1.289-27.658)$ & $0.022 *$ \\
\hline
\end{tabular}

Univariate cox hazard regression analysis. *indicates a significant difference $(P<0.05)$.

and normal volunteers, members of the miR-183 family were highly expressed in lung cancer primary tissues and sera. Moreover, we found that the expression levels of miR-96, miR-182, and miR-183 were higher in A549 and 95D cells than in $\mathrm{H} 1299$ and 95C cells, respectively. This implies that the miR-183 family might participate in tumor metastasis $[19,30,33,34]$. Consistent with this, other studies demonstrated that overexpressed miR-96 and miR-182 in melanoma cell lines and breast cancer cell lines resulted in enhanced oncogenic properties as well as invasion and metastasis in vitro [30,33]. Sarver et al. [19] showed that a reduction in miR-183 led to a decrease in migration in colon cancer and synovial sarcoma cell lines. Abraham et al. [34] reported that overexpression of miR-183 in medullary thyroid cancer predicted lymph node metastasis.

We note that opposite results have also been reported. According to one study, expression of miR-96 decreased cell invasion and migration in pancreatic cancer [35]. Another report demonstrated that miR-182 suppressed cell proliferation of lung cancer cell line A549 in vitro and tumor growth in vivo through its interference with the target gene cortactin $(C T T N)$ by epigenetic modification [36]. Others found that overexpression of miR183 inhibited migration and invasion of lung cancer and breast cancer cells, by targeting the protein ezrin $[22,37]$. These discrepancies might be due to different cancer cell lines used, and suggest that miRNA might have distinct functions depending upon cell type [38].

Our results demonstrate an association between the expressions of miR-183 and miR-182 and metastasis, invasion, advanced clinical stage, and tumor sizes of NSCLC. Together with other reports, they imply that
miR-182 and miR-183 might play a role in lung cancer invasion and metastasis, and progression of NSCLC $[28,30]$. Moreover, in our study patients with high tumor or serum levels of miR-96, miR-182, and miR-183 had shorter overall post-operative survival times. The hazard ratios adjusted for gender, age and tumor stage indicated that these miRNAs could be used independently for evaluating the prognoses of NSCLC patients.

In addition, our results demonstrated that serum miRNAs might be used as potential biomarkers for diagnosis and prognosis of lung cancers. Under lung cancer condition, miRNAs entered the circulation mainly from tumor cells [27]. One study showed that miRNAs in tissue specimens were not detected by Solexa sequencing in sera [39]. By comparing the expressions of miR-96, miR-182 and miR-183 in tumors and sera, our results suggest that the levels of serum and tumor miR-96 were correlated, while those of miR-182 and miR-183 were not. These results are consistent with reports from Mitchell [27] and $\mathrm{Hu}$ [39]. The actual role and functions of these miRNAs need to be further investigated.

\section{Conclusions}

Our results show that members of the miR-183 family, found in tumors and sera, may play a role in the development of NSCLC and have potential as biomarkers in the diagnosis and prognosis of lung cancer. We further demonstrate a positive correlation between expression levels of miR-96 in tumors and sera from NSCLC patients. Further study needs to be done to define the true value of combined expression profiles of the miR183 family in tumors and sera in the diagnosis and prognosis of lung cancer. 


\section{List of abbreviations}

Ct: cycle threshold; CTTN: cortactin; DMEM: Dulbecco's modified Eagle's medium; EGR1: early growth response 1; FOXO3 forkhead box O3; FOXO1: forkhead box 01; miRNA: microRNA; NCCN: National Comprehensive Cancer Network; NSCLC: non-small cell lung cancer; pCp-Cy3: 5'-cytidine bisphosphate-cyanine 3; PTEN: phosphatase and tensin homolog; RT: reverse transcription; qRT-PCR: quantitative real-time reverse transcription polymerase chain reaction; SAM: significance analysis of microarrays; SEM: standard error of the mean; snRNA: small nuclear RNA.

\section{Acknowledgements}

This research was supported by a grant from the Zhejiang Provincial Natural Science Foundation of China (No. Y2101391), a grant from the Medical Bureau of Zhejiang Province (No. 2009A210), and grants from the Science and Technology Bureau of Zhoushan (No. 20081059, No.091042 and No.10137) and from the Medical Bureau of Zhoushan (No. 2009B03). The authors would like to thank Medjaden Bioscience Limited for assisting in the preparation of this manuscript.

\section{Author details}

'Department of Cardio-Thoracic Surgery, Zhoushan Hospital of Zhejiang Province, Zhoushan, Zhejiang, 316004, 316004, China. ${ }^{2}$ Joint Laboratory of Immunogenomics, Zhoushan Hospital-BIG/CAS, Zhoushan, Zhejiang Province, 316004, China.

\section{Authors' contributions}

WYZ, XGL, and YKZ were involved in the conception and design of the study. WYZ, JYH, DDC, and YYH were involved in the provision of study material and patients. WYZ and XGL performed the data analysis and interpretation. WYZ wrote the manuscript. YKZ approved the final version. All authors read and approved the final manuscript.

\section{Competing interests}

The authors declare that they have no competing interests.

Received: 17 June 2011 Accepted: 15 September 2011 Published: 15 September 2011

\section{References}

1. Jemal A, Siegel R, Ward E, Hao Y, Xu J, Thun MJ: Cancer statistics, 2009. CA-Cancer J Clin 2009, 59:225-249.

2. Jay C, Nemunaitis J, Chen P, Fulgham P, Tong AW: miRNA profiling for diagnosis and prognosis of human cancer. DNA Cell Biol 2007, 26:293-300

3. Cummins J, Velculescu V: Implications of micro-RNA profiling for cancer diagnosis. Oncogene 2006, 25:6220-6227.

4. Yu SL, Chen HY, Chang GC, Chen CY, Chen HW, Singh S, Cheng CL, Yu CJ, Lee $Y C$, Chen HS: MicroRNA signature predicts survival and relapse in lung cancer. Cancer Cell 2008, 13:48-57.

5. Calin GA, Croce CM: MicroRNA-cancer connection: the beginning of a new tale. Cancer Res 2006, 66:7390-7394.

6. Volinia S, Calin GA, Liu CG, Ambs S, Cimmino A, Petrocca F, Visone R, lorio M, Roldo C, Ferracin M: A microRNA expression signature of human solid tumors defines cancer gene targets. Proc Natl Acad Sci 2006, 103:2257-2261.

7. Rosell R, Wei J, Taron M: Circulating microRNA signatures of tumorderived exosomes for early diagnosis of non-small cell lung cancer. Clin Lung Cancer 2009, 10:8-9.

8. Ventura A, Jacks T: MicroRNAs and cancer: short RNAs go a long way. Cell 2009, 136:586-591.

9. Yanaihara N, Caplen N, Bowman E, Seike M, Kumamoto K, Yi M, Stephens RM, Okamoto A, Yokota J, Tanaka T: Unique microRNA molecular profiles in lung cancer diagnosis and prognosis. Cancer cell 2006, 9:189-198.

10. Raponi M, Dossey L, Jatkoe T, Wu X, Chen G, Fan H, Beer DG: MicroRNA classifiers for predicting prognosis of squamous cell lung cancer. Cancer Res 2009, 69:5776-5783.

11. Galluzzi L, Morselli E, Vitale I, Kepp O, Senovilla L, Criollo A, Servant N, Paccard C, Hupe P, Robert T: MiR-181a and miR-630 regulate cisplatininduced cancer cell death. Cancer Res 2010, 70:1793-1803.
12. Zhao H, Shen J, Medico L, Wang D, Ambrosone CB, Liu S, Creighton C: A pilot study of circulating miRNAs as potential biomarkers of early stage breast cancer. PLoS One 2010, 5:876-887.

13. Resnick KE, Alder H, Hagan JP, Richardson DL, Croce CM, Cohn DE: The detection of differentially expressed microRNAs from the serum of ovarian cancer patients using a novel real-time PCR platform. Gynecol oncol 2009, 112:55-59.

14. Chen X, Ba Y, Ma L, Cai X, Yin Y, Wang K, Guo J, Zhang Y, Chen J, Guo X: Characterization of microRNAs in serum: a novel class of biomarkers for diagnosis of cancer and other diseases. Cell Res 2008, 18:997-1006.

15. Gokhale A, Kunder R, Goel A, Sarin R, Moiyadi A, Shenoy A, Mamidipally C, Noronha S, Kannan S, Shirsat N: Distinctive microRNA signature of medulloblastomas associated with the WNT signaling pathway. J Cancer Res Ther 2010, 6:521-529.

16. Lin $P, Y u$ S, Yang P: MicroRNA in lung cancer. Br J cancer 2010, 103:1144-1148

17. Schaefer A, Jung M, Mollenkopf HJ, Wagner I, Stephan C, Jentzmik F, Miller K, Lein M, Kristiansen G, Jung K: Diagnostic and prognostic implications of microRNA profiling in prostate carcinoma. Int I Cancer 2010, 126:1166-1176

18. Pineau P, Volinia S, McJunkin K, Marchio A, Battiston C, Terris B, Mazzaferro V, Lowe SW, Croce CM, Dejean A: miR-221 overexpression contributes to liver tumorigenesis. Proc Natl Acad Sci 2010, 107:264-269.

19. Sarver AL, Li L, Subramanian S: MicroRNA miR-183 functions as an oncogene by targeting the transcription factor EGR1 and promoting tumor cell migration. Cancer Res 2010, 70:9570-9580.

20. Bandres E, Cubedo E, Agirre X, Malumbres R, Zarate R, Ramirez N, Abajo A, Navarro A, Moreno I, Monzo M: Identification by Real-time PCR of 13 mature microRNAs differentially expressed in colorectal cancer and nontumoral tissues. Mol Cancer 2006, 5:29.

21. Navon R, Wang H, Steinfeld I, Tsalenko A, Ben-Dor A, Yakhini Z: Novel rankbased statistical methods reveal microRNAs with differential expression in multiple cancer types. PloS one 2009, 4:e8003.

22. Wang J, Chen J, Chang P, LeBlanc A, Li D, Abbruzzesse JL, Frazier ML, Killary AM, Sen S: MicroRNAs in plasma of pancreatic ductal adenocarcinoma patients as novel blood-based biomarkers of disease. Cancer Prev Res 2009, 2:807.

23. Livak KJ, Schmittgen TD: Analysis of relative gene expression data using real-time quantitative PCR and the 2 (-Delta Delta C (T)) method. Methods 2001, 25:402-408.

24. Liu X, Zhu W, Huang Y, Ma L, Zhou S, Wang Y, Zeng F, Zhou J, Zhang Y: High expression of serum miR-21 and tumor miR-200c associated with poor prognosis in patients with lung cancer. Med Oncol 2011.

25. Lu J, Getz G, Miska EA, Alvarez-Saavedra E, Lamb J, Peck D, SweetCordero A, Ebert BL, Mak RH, Ferrando AA: MicroRNA expression profiles classify human cancers. Nature 2005, 435:834-838.

26. Asaga $S$, Kuo $C$, Nguyen $T$, Terpenning $M$, Giuliano AE, Hoon DSB: Direct serum assay for microRNA-21 concentrations in early and advanced breast cancer. Clin Chem 2011, 57:84-91.

27. Mitchell PS, Parkin RK, Kroh EM, Fritz BR, Wyman SK, PogosovaAgadjanyan EL, Peterson A, Noteboom J, O'Briant KC, Allen A: Circulating microRNAs as stable blood-based markers for cancer detection. Proc Natl Acad Sci 2008, 105:10513-10518.

28. Boeri M, Verri C, Conte D, Roz L, Modena P, Facchinetti F, Calabr E, Croce CM, Pastorino U, Sozzi G: MicroRNA signatures in tissues and plasma predict development and prognosis of computed tomography detected lung cancer. Proc Natl Acad Sci 2011, 108:3713-3718.

29. Barshack I, Lithwick-Yanai G, Afek A, Rosenblatt K, Tabibian-Keissar H, Zepeniuk M, Cohen L, Dan H, Zion O, Strenov Y: MicroRNA expression differentiates between primary lung tumors and metastases to the lung. Pathol Res Prac 2010, 206:578-584.

30. Segura MF, Hanniford D, Menendez S, Reavie L, Zou X, Alvarez-Diaz S, Zakrzewski J, Blochin E, Rose A, Bogunovic D: Aberrant miR-182 expression promotes melanoma metastasis by repressing $\mathrm{FOXO} 3$ and microphthalmia-associated transcription factor. Proc Natl Acad Sci 2009, 106:1814-1819.

31. Guttilla IK, White BA: Coordinate regulation of FOXO1 by miR-27a, miR96, and miR-182 in breast cancer cells. J Biol Chem 2009, 284:23204-23216.

32. Myatt SS, Wang J, Monteiro LJ, Christian M, Ho KK, Fusi L, Dina RE, Brosens JJ, Ghaem-Maghami S, Lam EWF: Definition of microRNAs that 
repress expression of the tumor suppressor gene FOXO1 in endometrial cancer. Cancer Res 2010, 70:367-377.

33. Li J, Fu H, Xu C, Tie Y, Xing R, Zhu J, Qin Y, Sun Z, Zheng X: miR-183 inhibits TGF- $\beta 1$-induced apoptosis by downregulation of PDCD 4 expression in human hepatocellular carcinoma cells. BMC cancer 2010 10:354.

34. Abraham D, Jackson NE, Gundara JS, Zhao J, Gill AJ, Delbridge L, Robinson B, Sidhu S: MicroRNA profiling of sporadic and hereditary medullary thyroid cancer identifies predictors of nodal metastasis, prognosis and potential therapeutic targets. Clin Cancer Res 2011, 17:4772-4781.

35. Yu S, Lu Z, Liu C, Meng Y, Ma Y, Zhao W, Liu J, Yu J, Chen J: miRNA-96 suppresses KRAS and functions as a tumor suppressor gene in pancreatic cancer. Cancer Res 2010, 70:6015-6025.

36. Zhang L, Liu T, Huang Y, Liu J: microRNA-182 inhibits the proliferation and invasion of human lung adenocarcinoma cells through its effect on human cortical actin-associated protein. Int J Mol Med 2011, 28:381-383.

37. Lowery AJ, Miller N, Dwyer RM, Kerin MJ: Dysregulated miR-183 inhibits migration in breast cancer cells. BMC cancer 2010, 10:502.

38. Hyun S, Lee JH, Jin H, Nam JW, Namkoong B, Lee G, Chung J, Kim VN: Conserved MicroRNA miR-8/miR-200 and its target USH/FOG2 control growth by regulating PI3K. Cell 2009, 139:1096-1108.

39. Hu Z, Chen X, Zhao Y, Tian T, Jin G, Shu Y, Chen Y, Xu L, Zen K, Zhang C: Serum microRNA signatures identified in a genome-wide serum microRNA expression profiling predict survival of non-small cell lung cancer. J Clin Oncol 2010, 28:1721-1726.

\section{Pre-publication history}

The pre-publication history for this paper can be accessed here: http://www.biomedcentral.com/1471-2407/11/393/prepub

doi:10.1186/1471-2407-11-393

Cite this article as: Zhu et al:: Overexpression of members of the microRNA-183 family is a risk factor for lung cancer: A case control study. BMC Cancer 2011 11:393.

\section{Submit your next manuscript to BioMed Central} and take full advantage of:

- Convenient online submission

- Thorough peer review

- No space constraints or color figure charges

- Immediate publication on acceptance

- Inclusion in PubMed, CAS, Scopus and Google Scholar

- Research which is freely available for redistribution

Submit your manuscript at www.biomedcentral.com/submit
Biomed Central 